\title{
Transverse wave propagation in viscoelastic single-walled carbon nanotubes with surface effect based on nonlocal second-order strain gradient elasticity theory
}

\author{
Huili Guo ${ }^{1}$, Fulin Shang ${ }^{2}$, and Tianhu $\mathrm{He}^{3}$ \\ ${ }^{1}$ Lanzhou Jiaotong University \\ ${ }^{2}$ Xi'an Jiaotong University \\ ${ }^{3}$ Lanzhou University of Technology
}

August 31, 2020

\begin{abstract}
Nowadays, carbon nanotubes (CNTs) have been used as one of the most promising candidates for nanodevices (or nanoelectronics) and super-strong reinforcement fibers in nanocomposites. This work aims to investigate the transverse wave propagation in viscoelastic single-walled carbon nanotubes (SWCNTs) adhered by surface material. In the context of nonlocal second-order strain gradient elasticity theory, the characteristic equation of wave motion of viscoelastic SWCNTs with surface effect is systematically formulated. The analytical expression, i.e. closed-form dispersion relation between the wave frequency (or phase velocity) and the wave number, are derived for the frequency and phase velocity of the wave motion. The size-dependent characteristic lengths, surface effects and structural damping on the properties of wave propagation are elucidated in detail.
\end{abstract}

\section{Hosted file}

Main Document.doc available at https://authorea.com/users/355174/articles/478516-transversewave-propagation-in-viscoelastic-single-walled-carbon-nanotubes-with-surface-effectbased-on-nonlocal-second-order-strain-gradient-elasticity-theory

\section{Hosted file}

Figures.docx available at https://authorea.com/users/355174/articles/478516-transverse-wavepropagation-in-viscoelastic-single-walled-carbon-nanotubes-with-surface-effect-based-onnonlocal-second-order-strain-gradient-elasticity-theory 